\title{
Research on Accounting of Cultural Relics and Cultural Assets in Colleges and Universities
}

\author{
Guanqiong Yan \\ Finance Department \\ Xi'an Academy of Fine Arts \\ Xi'an, Shaanxi \\ 479731160@qq.com
}

\begin{abstract}
Colleges and universities have implemented the "Government Accounting System" since 2019, cultural relics and cultural assets are an important public resource for the control and management of colleges and universities, they need to be confirmed, measured and included in the government financial report in accordance with the accrual accounting basis. This paper discusses the definition, confirmation and measurement of cultural relics and cultural assets in colleges and universities. This paper believes that cultural relics and cultural assets include tangible "cultural relics" and intangible "cultural assets", and most of the cultural relics and cultural assets owned or controlled by universities are cultural relic assets. Cultural relics and cultural assets that can obtain reliable costs should be measured at historical cost, and for costs that cannot be reliably obtained, they should be measured at a nominal cost. Scientifically and accurately accounting and reporting on cultural assets of colleges and universities not only help colleges and universities adapt to the requirements of the government accounting system, but also improve the information quality and integrity of government financial reports. At the same time, it is in line with international standards and is also conducive to strengthening the government's management, utilization and protection of cultural assets.
\end{abstract}

Keywords-Cultural relics and cultural assets; colleges and universities; accounting

\section{INTRODUCTION}

The report of the 19th National Congress of the Communist Party of China stated that it is necessary to "strengthen the protection and utilization of cultural relics and the inheritance of cultural heritage protection."The cultural relics and cultural assets of colleges and universities are not only an important asset of the school, but also an important foundation for the cultural innovation of colleges and universities. They are an important component of social cultural relics and cultural resources, as well as an important carrier for inheriting social culture. At present, many colleges and universities hold archives, art galleries, museums and other special places to preserve and manage cultural relics and cultural assets. While teaching and learning within the school's teachers and students and academic research, they also openly display to the teachers, students in the school and the public. It is highlighting educational functions, cultural inheritance functions, and social service functions of colleges and

Fund Project: 2018 Xi'an Academy of Fine Arts Humanities and Social Sciences Research Project " Research on Artwork'Accounting Treatment of Colleges and Universities " Project No. 2018XK038 universities.

Therefore, scientifically and accurately accounting and reporting cultural relics and cultural assets of colleges and universities not only helps colleges and universities adapt to the requirements of the government accounting system, but also improves the information quality and integrity of government financial reports, and it provides basic data for economic operation analysis, as well as reforms to improve the level and efficiency of financial management. It also improves government transparency to facilitate public supervision and improves the scientific and forward-looks nature of macro-decision. At the same time it integrates with international standards, it is also conducive to strengthening the government's management, utilization and protection of cultural relics and cultural assets.

\section{CHARACTERISTICS OF CULTURAL RELICS AND CULTURAL ASSETS IN COLLEGES AND UNIVERSITIES}

Different from other administrative institutions, colleges and universities are also responsible for the social public needs of opening up to the public while taking on the important responsibility of educating. The cultural relics and cultural assets of colleges and universities are not only an important asset of the school, but also an important foundation for the cultural innovation of colleges and universities. They are an important component of social cultural relics and cultural resources, as well as an important carrier for inheriting social culture.

\section{A. Large variety and quantity of cultural relics and cultural assets in colleges and universities}

The cultural relics and cultural assets of colleges and universities not only involve historical relicslike artworks, ancient books, oracle bones, bronzes, paintings, jade articles, fabrics, etc., but also include building assets such as Peking University's unnamed Lake, and Tsinghua University Auditorium, even more than some museums. They are an important part of university assets and should be included in the accounting system and reported for disclosure. 


\section{B. Functional diversity of cultural relics and cultural assets in colleges and universities}

From the perspective of cultural relics, the cultural relics and cultural assets of colleges and universities have important historical value, artistic value and scientific value. From a practical point of view, the cultural relics and cultural assets of colleges and universities have the educational value of inheriting culture and popularizing knowledge. It can meet the needs of the public through exhibitions and other forms. For example, the teachers and students of Xi'an Academy of Fine Arts rely on the art museum to conduct teaching and learning and academic research on ancient and modern art works and folk art collections. The public can also visit during museum exhibitions; the museum of medical history of Shaanxi University of Chinese Medicine is not only a provincial museum, but also a science and education publicity and education base for Chinese medicine.

\section{Professional characteristics of cultural relics and cultural assets in colleges and universities}

The cultural relics and cultural assets of colleges and universities are closely related to the professional nature of the school and have distinctive professional characteristics. For example, various ancient medical inscriptions collected by the Museum of Medical History of Shaanxi University of Chinese Medicine: the "Experience Recorded Monument" discovered by Xingping in Shaanxi Province, is a very rare stone carving art treasure. Therefore, different colleges and universities need to classify their cultural relics and cultural assets according to their actual conditions.

\section{The Definition of Cultural Relics AND Cultural ASSETS}

The concept or definition of cultural relics and cultural assets by academia and accounting organizations at home and abroad has not been uniformly defined.

Foreign government accounting directly uses "Cultural Heritage" or "Heritage" to calculate and report cultural assets of cultural relics. The International Public Sector Accounting Standards issued by the International Public Accountants' Accounting Board under the International Federation of Accountants clearly defines cultural heritage as "cultural, environmental or historically significant assets", usually including history architecture and monuments, archaeological remains, nature reserves and art. Among them, the tangible cultural heritage is calculated in the No. 17 "Property, Plant and Equipment", and the intangible cultural heritage is standardized in No. 31 "Intangible Assets".[1-2] Statement of Federal Financial Accounting Standards Code No.29, "Heritage Assets and Stewardship Land", defines the cultural heritage as "fixed assets with important educational, cultural, and natural significance", and divided into two categories: collection cultural heritage and non-collection cultural heritage. Collection cultural heritage includes museum collections, art collections, etc. Non-collection cultural heritage includes parks and monuments.[3] The concept of cultural heritage or heritage applied by most international organizations and western countries in the field of government accounting emphasizes that its connotation has important historical, cultural and educational significance and classifies it as a tangible culture of material form. Intangible cultural heritage in the form of heritage and non-material forms is accounted for in terms of fixed assets and intangible assets in the field of government accounting.

The "Non-profit Organization Accounting System" promulgated by the Ministry of Finance in 2005 clearly defines cultural relics of cultural assets as "historical artifacts, artworks and other cultural or historical values for exhibition, education or research purposes and for long-term or permanent Saved collections, etc.".[4]This system accounts for cultural relics and cultural assets as fixed assets and is reflected in the balance sheet. The "Accounting System for Institutions" promulgated by the Ministry of Finance in 2012 and the "Accounting System for Higher Education" issued in 2013 use "relics and exhibits" to calculate and report cultural assets of cultural relics, which belong to one of the six categories of fixed assets. However, the definitions of "cultural objects and exhibits" have not been clearly stated. [56]It can be seen that in the previous system, China believed that the cultural relics and cultural assets belonged to fixed assets and only included articles with physical forms.

The definition of "cultural relics" and "culture" in "CiHai" is as follows: Cultural relics refer to human cultural relics that exist in society or buried underground. China's state-protected cultural relics include:(1)ancient cultural sites with historical, artistic, and scientific values, ancient tombs, ancient buildings, cave temples, and stone carvings;(2)related to major historical events, revolutionary movements, and famous figures, Buildings, ruins, monuments with commemorative significance, educational significance and important historical values;(3)precious works of art, arts and crafts of all ages in history;(4)important revolutionary literature, and history, art and Manuscripts of scientific value, old books and materials; (5)representative objects reflecting social systems, social production, and social life in all ages. Culture broadly refers to the sum of the material and spiritual productive capacity and the material and spiritual wealth created by human beings in the process of social practice. It narrow sense refers to spiritual production capacity and spiritual products, including all forms of social consciousness.[7]

China is one of the most complete countries in the world with the world's cultural heritage category. It is also the country with the largest number of natural and cultural heritages in the world. It encompasses various cultural relics such as cultural relics, buildings and sites, as well as various traditional humanistic techniques. Therefore, this paper believes that cultural relics and cultural assets in Colleges and Universities cover the two concepts of "cultural relics" and "cultural assets". Cultural relics refer to "historical, artistic and scientific cultural relics for exhibition, education or research purposes, including ancient ruins, ancient tombs, ancient buildings, cave temples, stone carvings, murals, modern important historical sites and representative buildings and other non-movable cultural relics, and movable artifacts such as important objects, works of art, literature, manuscripts, books and materials in various eras in history.” Cultural assets refer to "all kinds of traditional cultural expressions that have 
been passed down from generation to generation that Exist in non-material forms, using sound, image and skill as means of expression, including oral traditions, traditional performing arts, folk activities and ceremonies and festivals, folk traditional knowledge and practices related to nature and the universe, traditional handicraft skills, and cultures associated with these traditional cultural expressions. The vast majority of the cultural relics and cultural assets owned and managed by various universities are cultural assets such as various historical sites, works of art, and architectural complexes.

\section{The CONFIRMATion OF CUltural RELICS AND Cultural Assets IN COLLEGES AND UNIVERSITIES}

In the "Basic Standards for Government Accounting", assets refer to economic resources or events formed by government accounting entities in the past. They are controlled by government accounting entities and expected to generate economic resources with service potential or inflow of economic benefits. Cultural relics and cultural assets provide social public services through knowledge and culture. The essence of colleges' control and possession of cultural relics and cultural assets is the function of public management and public service. The cultural relics and cultural assets themselves have the function of inheriting historical culture and national spirit. They are the best basis for studying the development of human civilization, and also a rich resource for patriotism and revolutionary tradition education. Therefore, cultural relics and cultural assets have important historical value, academic value and educational significance, and usually have entertainment and enjoyment. So they meet the conditions for government assets to expect service potential.

Some cultural relics and cultural assets have the following characteristics: the cost can not be reliably obtained; they cannot be sold externally to make profits; the cost of reconstruction and expansion in order to increase the use efficiency of cultural relics and cultural assets in the holding process, and the expenditure on daily maintenance to ensure the normal use of assets, which cause the university to generate net cash outflow rather than inflow. But the liability itself comes from the maintenance of cultural relics and cultural assets, rather than the cultural relics and cultural assets itself.

Therefore, this paper believes that cultural relics and cultural assets in colleges and universities meet the definition of assets under the government accounting system. They should be included in the balance sheet and fully reflected in the government financial report to fully reflect the responsibilities of the trustees of the cultural assets of cultural relics.

\section{Measurement of Cultural Relics And Cultural ASSETS IN COLLEGES AND UNIVERSITIES}

On the basis of the confirmation of cultural relics of cultural assets, it is necessary to measure the book value to reflect the important value of cultural relics and cultural assets in history and culture. Scientific and accurate measurement of cultural relics and cultural assets will help improve the government's management level of cultural relics and cultural assets. It will strengthen the protection of cultural relics and cultural assets while satisfying the social public needs such as the educational significance and cultural heritage. And it will maintain the world cultural diversity and creativity, and promote the common development of mankind.

\section{A. Initial measurement}

The Major western countries and international organizations, such as the International Public Sector Accounting Standards Board, the Federal Government Accounting Standards Board, and the French Public Accounting Standards Committee, consider those cultural relics and cultural assets are measured at historical cost, and fair value, and replacement cost, and nominal value, etc. These four measurement principles have their own applicability and limitations in practice.

The historical cost is measured based on the acquisition cost when the economic business occurs. The original certificate is used as the measurement basis. The data is easy to obtain, simple and easy to operate, and it is not necessary to adjust the accounts frequently. It can prevent the accounting records from being changed arbitrarily and maintain the reliability of accounting information. This measurement model is applicable to newly acquired cultural relics and cultural assets, and its historical cost is relatively easy to obtain and true and reliable. However, most cultural relics and cultural assets are old, and their historical costs are difficult to obtain. Even if they are available, they cannot accurately reflect their current value.

Fair value is assuming that there are active markets of their own or similar, and the prices determined by the buyers and sellers who are familiar with the market conditions under fair trade conditions and voluntary conditions. In reality, some types of cultural relics are strictly prohibited from buying or selling. If the market is unpopular, even if there is an active market, it is necessary to combine the insurance value method or the expert evaluation method to obtain fair value, which is costly and difficult to carry out.

The replacement cost refers to the amount of cash or cash equivalents required to regain the same asset in accordance with current market conditions. It sometimes has no practical significance in the measurement of cultural relics and cultural assets. Rebuilding the value of cultural relics and cultural assets cannot be used to accurately estimate its original value. For example, the cost of reconstructing the Rosetta Stone in the collection of the British Museum is only a currency figure, which does not reflect the value of the stone.[8]

For those cultural relics and cultural assets that have been in possession for a long time, or have been unable to obtain relevant evidence for various reasons when accepting donations and free of charge, they can be accounted for by the nominal amount " 1 " when the accurate cost information cannot be determined. Nominal amount " 1 " can symbolically reflect their value. In this way, it can not only clearly define the existence of physical assets in the account, but also facilitate the management of the asset management department of the university, and effectively ensure that cultural relics and cultural assets are not lost or hidden. 
This paper believes that the value measurement of cultural relics and cultural assets should use scientific, reasonable and feasible measurement methods. It is necessary to select the appropriate measurement not only from the economic value of cultural relics and cultural assets, but also from the perspective of cultural relics' protection and management and meeting public demand. Therefore, in order to accurately provide accounting information of cultural relics and cultural assets, it needs to measure the cultural assets of cultural relics that can be reliably obtained by historical cost method, on the basis of comprehensive consideration of the particularity of cultural relics and cultural assets. For example, newly purchased cultural relics and cultural assets should be recorded at the purchase price, relevant taxes and other expenses (such as transportation costs, installation fees, loading and unloading fees, etc.) that may be attributed to the assets before they are used for the intended purpose; Cultural relics and cultural assets that cannot be reliably obtained at cost shall be measured by the nominal amount "1" and its detailed information shall be disclosed in the notes to the statement.

\section{B. Subsequent measurement}

The subsequent measurement of cultural relics and cultural assets of colleges and universities mainly focuses on whether to depreciate or amortize them, as well as the cost or expense of repairing and maintaining them.

The International Public Sector Accounting Standards Board and the Federal Government Accounting Standards Board depreciate or amortize cultural relics and cultural assets. The French Public Accountancy Standards Committee is one of the few organizations that does not depreciate or amortize cultural relics and cultural assets. China's "Government Accounting System" does not stipulate depreciation or amortization of cultural assets of cultural relics. Due to the uncertain service life of cultural relics and cultural assets, some assets are stored for a long time, so their specific service life is difficult to estimate; Due to the unique historical, cultural or educational, and collection characteristics of cultural relics and cultural assets, the expected service or economic benefits of such assets are increased over time; China's cultural relics and cultural assets are numerous, and depreciation and amortization also require a lot of manpower and material resources which in turn increase the related costs, so there is no need to depreciate the cultural relics and cultural assets.

In the process of holding cultural relics and cultural assets in the later period, subsequent expenditures such as repairing to prolong the preservation of cultural relics and cultural assets should be included in the cost of cultural relics and cultural assets; Subsequent expenditures such as maintenance incurred to enable the cultural assets of cultural relics to exist normally should be included in the expenses. And this information can be disclosed in the notes to the report.

\section{CONCLUSION}

This paper discusses the accounting of cultural relics and cultural assets in colleges and universities. It believes that cultural relics and cultural assets include tangible "cultural assets" and intangible "cultural assets". Most of the cultural relics and cultural assets owned and controlled by universities are cultural relic assets. Cultural relics and cultural assets that can obtain reliable costs should be measured at historical cost, If the costs of cultural relics and cultural assets that cannot be reliably obtained, these assets should be measured at nominal cost. Colleges and universities are important units for owning and managing cultural relics and cultural assets. They have the responsibility to accurately account the economic value of cultural relics and cultural assets, and to provide transparent financial information and non-financial information. They provide a solid foundation for strengthening the inheritance and protection of cultural relics and cultural assets in China, as well as promote scientific research. They also conduct patriotism and revolutionary education, and build a socialist spiritual civilization and material civilization.

\section{REFERENCES}

[1] International Public Sector Accounting Standards Board (IPSASB)[S] 2007. IPSAS 17 Property, Plant and Equipment.

[2] International Public Sector Accounting Standards Board (IPSASB)[S].2010.IPSAS31 Intangible Assets.

[3] Federal Accounting Standards Advisory Board (FASAB)[S] 2005.SFFAS29 Heritage Assets and Stewardship Land.

[4] Civil non-profit organization accounting system [S] Ministry of Finance. 2005. (In Chinese)

[5] Institutional Accounting System [S] Ministry of Finance. 2012. (In Chinese)

[6] Higher education accounting system [S] Ministry of Finance. 2013. (In Chinese)

[7] Xia Linong, Chen Zhili. CiHai (2009 Edition) [M]. Shanghai: Shanghai Dictionary Press. 2010. (In Chinese)

[8] Barton.Accountingforpublicheritagefacilitiesassetsorliabilitiesofthegover nment?[J]. Accounting, Auditing \& AccountabilityJournal. 2000.13(2): $219-235$. 